\title{
Influence of QMix Irrigant on the Accuracy of Four Different Electronic Apex Locators
}

\author{
${ }^{1}$ Mustafa Murat Koçak, ${ }^{2}$ Sibel Koçak, ${ }^{3}$ Baran C Sağlam, ${ }^{4}$ Sevinç A Türker
}

\begin{abstract}
The aim of this study was to compare the accuracy of four different electronic apex locators in the presence of various irrigation solutions or dry canal condition. Nineteen mandibular incisor teeth were selected. The real working lengths (RWL) of teeth were measured with \#15 K-file. The electronic working lengths (EWLs) were measured with Root ZX mini, Raypex 6, iPex II, and Propex II under the condition of dry canal and in the presence of sodium hypochlorite and QMix. The difference between EWL and RWL was calculated. Root ZX mini was more accurate than Propex II under dry condition. No difference was found between the electronic apex locators in the presence of sodium hypochlorite ( $\mathrm{NaOCl})$. In the presence of QMix, Propex II and Root ZX mini demonstrated more accurate measurements than iPex II. Root ZX mini was found more accurate under dry condition than in the presence of QMix. Raypex 6 demonstrated more accuracy in the presence of QMix when compared with $\mathrm{NaOCl}$. iPex II showed similar measurements with all tested solutions. Propex II was more accurate in the presence of QMix. All devices can be considered reliable when used with QMix irrigation solution and with any irrigant.
\end{abstract}

Keywords: Apex locator, $\mathrm{NaOCl}, \mathrm{QMix}$, Working length determination.

How to cite this article: Koçak MM, Koçak S, Sağlam BC, Türker SA. Influence of QMix Irrigant on the Accuracy of Four Different Electronic Apex Locators. Int J Experiment Dent Sci 2016;5(1):23-27.

Source of support: This study was financially supported by the Scientific Research and Development Office of Bülent Ecevit University (Grant no. 2013-27194235-02).

\section{Conflict of interest: None}

\section{INTRODUCTION}

The accurate determination of real working length (RWL) has a major impact on the outcome of root canal treatment. ${ }^{1}$ An essential prerequisite is the establishment of correct working length during root canal preparation, as failure to do so may result in accidental extrusion of

\footnotetext{
${ }^{1,2}$ Associate Professor, ${ }^{3,4}$ Assistant Professor

${ }^{1-4}$ Department of Endodontics, Faculty of Dentistry, Bülent Ecevit University, Kozlu, Zonguldak, Turkey

Corresponding Author: Mustafa Murat Koçak, Assistant Professor, Department of Endodontics, Faculty of Dentistry Bülent Ecevit University, Kozlu, Zonguldak-67600, Turkey Phone: 0903722614580, Fax: 0903722613403, e-mail: mmuratkocak@yahoo.com
}

the irrigant, dressing, or filling and persistent periapical inflammation and postoperative pain. ${ }^{2}$

The traditional method used to determine RWL is based on the radiographic visualization of an instrument placed in the root canal. Radiographs provide a twodimensional (2D) image of a three-dimensional (3D) structure; they are subject to distortion and magnification and may not blot out the apical foramen localization because of anatomic deviations. ${ }^{3}$ Recently, the electronic method for working length determination has gained popularity. It has been reported that radiographic methods for tooth length determination might be less accurate than the electronic method. ${ }^{4}$ Despite having an accuracy of $80-90 \%$ in most root canals, their performance can be limited by multiple factors: the presence of a nearby metallic restoration or vital tissue, the type of any electrolytes in the canals, the diameter of the apical foramen, the absence/presence of apical constriction, and the size of file in use. ${ }^{2}$ The electrolytes in root canals are considered to be one of the main factors that affect the precision of measurements made by electronic apex locators (EALs). ${ }^{3}$ Since various irrigation solutions are used during endodontic practice, their effects on the accuracy of EALs must be evaluated.

Sodium hypochlorite $(\mathrm{NaOCl})$ is a commonly used irrigation solution in endodontic practice. The utilization of $\mathrm{NaOCl}$ irrigant in endodontics is justified by its undeniable importance as a result of both its wide-spectrum antimicrobial activity and its properties as a tissue solvent. ${ }^{5} \mathrm{NaOCl}$ is an effective organic tissue solvent, but it is unable to remove the smear layer by itself. ${ }^{5}$ Current literature contains limited data about the QMix (Dentsply Tulsa Dental, Tulsa, OK, USA) irrigation solution. QMix contains ethylenediaminetetraacetic acid (EDTA), chlorhexidine (CHX), and a detergent. QMix is effective at removing smear layer and contains antimicrobial agents. ${ }^{5}$ The ability to remove smear layer by QMix was comparable to EDTA, and QMix was superior to CHX and MTAD in killing Enterococcus faecalis in biofilm culture. ${ }^{6}$

The aim of this in vitro study was to evaluate the effect of QMix solution on the accuracy of four different EALs in comparison with $\mathrm{NaOCl}$ and dry condition. The null hypothesis was that the presence of QMix will not adversely affect the accuracy of the EALs. 


\section{MATERIALS AND METHODS}

Nineteen extracted single-rooted mandibular incisors were selected. After extraction, all teeth were kept in saline solution. Then the teeth were placed in $2.5 \%$ $\mathrm{NaOCl}$ solution for 2 hours and organic residues were removed. The teeth were numbered and decoronated at the cementoenamel junction with a diamond disk to produce a flat surface for the precise location of the rubber stop.

Gates Glidden burs (\#06, \#08, and \#10; DentsplyMaillefer, Ballaigues, Switzerland) were used to flare the coronal third of each canal. The patency of the apical foramen was verified using a \#15 K-file. All teeth were radiographed in both mesiodistal and buccolingual directions to verify absence of root resorption.

The RWL was measured by inserting a \#15 stainless steel file (VDW Antaeos, Munich, Germany) with a silicone stop, until the tip of the file was observed at the level of the apical foramen. The distance between the file tip and stopper adjacent to the flat, horizontal surface of the root was measured with a digital caliper at $0.02-\mathrm{mm}$ accuracy. The measurements were repeated three times for each canal and averaged.

All specimens and an apex locator clip were embedded in an alginate model to simulate the periodontal ligament specially developed to test EALs. ${ }^{4}$ The specimens were kept in position until the alginate had set completely. All measurements were made in an interval of 2 hours, with the alginate kept sufficiently humid for this time.

Four different EALs were used: Root ZX mini (J Morita Co., Kyoto, Japan), Raypex 6 (VDW, Munich, Germany), iPex II (NSK, Tochigi, Japan), and Propex II (Dentsply Maillefer, Ballaigues, Switzerland).

To determine the influence of irrigation solution, the following measurements were performed: Without irrigating solution (dry canal), in the presence of $2.5 \%$ $\mathrm{NaOCl}$, and in the presence of QMix irrigation solutions. Initially, all root canals were dried with paper points for dry canal measurements. In the groups including irrigation solution, a total of $2.5 \mathrm{ml}$ of each solution was used to irrigate each root canal. After the measurements with $\mathrm{NaOCl}$ were completed, the root canals were irrigated with $2.5 \mathrm{ml}$ of distilled water. The dryness of root canals was checked with paper points carefully before the measurements with QMix irrigating solution were initiated.

The EALs were used in accordance with the manufacturers' instructions. All measurements were recorded and were considered valid if the instrument remained stable for at least 5 seconds. Three measurements were taken, averaged, and recorded in terms of millimeters.

Each electronic working length (EWL) was measured by two examiners and the inter-examiner agreement was verified. To obtain a consistent EWL, new measurements were obtained when there was a discrepancy among the examiners' results. The evaluators were unaware of the preliminary measurements of the RWL.

The difference between measurements was calculated by subtracting RWL from EWL for each tooth. Positive values indicated measurements that were long of the apical constriction, negative values indicated measurements that were short of the apical constriction, and 0.0 values were considered coinciding measurements.

Statistical analysis was performed with Statistical Package for the Social Science (SPSS) version 18.0 software (SPSS Inc., Chicago, IL, USA). Distribution of data was determined by Shapiro-Wilks test. Descriptive statistics were expressed as mean \pm standard deviation. Variables were compared with the repeated measures analysis of variance or the Friedman test. Bonferroni test was used for post hoc test after repeated measures analysis of variance. The Wilcoxon test with the Bonferroni correction was used as a post hoc test, if the Friedman test is statistically significant. A p-value of less than 0.05 was considered statistically significant for all tests.

\section{RESULTS}

The mean values and standard deviations for all groups are listed in Table 1. Root ZX mini was more accurate than Propex II under dry condition ( $\mathrm{p}=0.016)$. No difference was found between the EALs in the presence of $\mathrm{NaOCl}$. In the presence of QMix, Propex II and Raypex 6 demonstrated more accurate measurements than iPex II and Root ZX mini of the time to $\pm 0.5 \mathrm{~mm}(\mathrm{p}<0.001)$. However, no difference was found when $\pm 1 \mathrm{~mm}$ was considered.

When the EALs were compared, Root ZX mini was found more accurate under dry condition than in the presence of QMix solution ( $p=0.003)$. Raypex 6 demonstrated more accuracy in the presence of QMix

Table 1: The mean values and standard deviations for all groups

\begin{tabular}{lllll}
\hline Irrigation solution & Root ZX mini (mean \pm SD) & Raypex 6 (mean \pm SD) & iPex II (mean \pm SD) & Propex II (mean \pm SD) \\
\hline Dry & $-0.5221 \pm .44094$ & $-0.6674 \pm 0.32685$ & $-0.6940 \pm 0.3925$ & $-0.7821 \pm 0.3915$ \\
NaOCl & $-0.7463 \pm 0.44942$ & $-0.6937 \pm 0.39924$ & $-0.7311 \pm 0.41453$ & $-0.7837 \pm 0.38287$ \\
QMix & $-0.6900 \pm 0.31581$ & $-0.4974 \pm 0.36600$ & $-0.5879 \pm 0.28897$ & $-0.3926 \pm 0.33255$ \\
\hline
\end{tabular}


when compared with $\mathrm{NaOCl}(\mathrm{p}=0.008)$. iPex II showed similar measurements with all tested solutions and conditions. Propex II was more accurate in the presence of QMix solution ( $\mathrm{p}<0.001)$.

The accuracies of EALs in establishing the working length were as follows:

Root ZX mini: With dry canal, it was accurate $52.6 \%$ of the time to $\pm 0.5 \mathrm{~mm}$ and $89.4 \%$ of the time to $\pm 1 \mathrm{~mm}$; with $2.5 \% \mathrm{NaOCl}$, it was accurate $47.3 \%$ of the time to $\pm 0.5 \mathrm{~mm}$ and $78.9 \%$ of the time to $\pm 1 \mathrm{~mm}$; with QMix, it was accurate $31.5 \%$ of the time to $\pm 0.5 \mathrm{~mm}$ and $89.4 \%$ of the time to $\pm 1 \mathrm{~mm}$.

Raypex 6: With dry canal, it was accurate $42.1 \%$ of the time to $\pm 0.5 \mathrm{~mm}$ and $89.4 \%$ of the time to $\pm 1 \mathrm{~mm}$; with $2.5 \% \mathrm{NaOCl}$, it was accurate $42.1 \%$ of the time to $\pm 0.5 \mathrm{~mm}$ and $78.9 \%$ of the time to $\pm 1 \mathrm{~mm}$; with QMix, it was accurate $57.9 \%$ of the time to $\pm 0.5 \mathrm{~mm}$ and $94.7 \%$ of the time to $\pm 1 \mathrm{~mm}$.

iPex II: With dry canal, it was accurate $36.9 \%$ of the time to $\pm 0.5 \mathrm{~mm}$ and $78.9 \%$ of the time to $\pm 1 \mathrm{~mm}$; with $2.5 \% \mathrm{NaOCl}$, it was accurate $36.9 \%$ of the time to $\pm 0.5 \mathrm{~mm}$ and $73.6 \%$ of the time to $\pm 1 \mathrm{~mm}$; with QMix, it was accurate $42.1 \%$ of the time to $\pm 0.5 \mathrm{~mm}$ and $89.4 \%$ of the time to $\pm 1 \mathrm{~mm}$.

Propex II: With dry canal, it was accurate $36.9 \%$ of the time to $\pm 0.5 \mathrm{~mm}$ and $78.9 \%$ of the time to $\pm 1 \mathrm{~mm}$; with $2.5 \% \mathrm{NaOCl}$, it was accurate $42.1 \%$ of the time to $\pm 0.5 \mathrm{~mm}$ and $78.9 \%$ of the time to $\pm 1 \mathrm{~mm}$; with QMix, it was accurate $68.4 \%$ of the time to $\pm 0.5 \mathrm{~mm}$ and $94.7 \%$ of the time to $\pm 1 \mathrm{~mm}$.

\section{DISCUSSION}

In the present study, the distance between the file tip and the major foramen was calculated. Various studies have used the major foramen as a reference point. ${ }^{7,8}$ The distance between the apical major foramen and the minor foramen varies from 0.5 to $1.0 \mathrm{~mm}$ for teeth of different ages. ${ }^{9}$ Taking into account the enormous anatomical variability of the apical region, some authors take $\pm 1 \mathrm{~mm}$ to be the acceptable error range. ${ }^{10}$ Determination of working length with a variation of $\pm 1 \mathrm{~mm}$ was considered as acceptable. ${ }^{1,10}$ In the present study, when the mean values were considered, none of the tested devices measured the EWL beyond apical constriction. All devices demonstrated significantly short working length determination when compared with RWL. However, when variation of $\pm 1 \mathrm{~mm}$ as acceptable was considered, all devices demonstrated reliable results.

The Root ZX is one of the most studied EALs. Similar to our results, evaluation of Root ZX showed that the device gave reliable working length determinations without going beyond the apical foramen in human extracted teeth. ${ }^{11}$ Root $\mathrm{ZX}$ can determine working length similarly in both in vivo and in vitro conditions, with no statistically significant differences. ${ }^{12}$ The in vivo accuracy of Root ZX was $91.7 \%$ for the apical constriction location..$^{13}$ Similar results were observed, in vitro, by D'Assunção et $\mathrm{al}_{1}{ }^{14}$ presenting an effectiveness of $89.7 \%$ for Root ZX. Root ZX mini has a similar working principle with Root ZX and can measure in both wet or dry canal conditions. ${ }^{15}$ Root $Z X$ was shown to have a significantly higher accuracy in dry canals when compared with moistened $\mathrm{H}_{2} \mathrm{O}_{2}{ }^{16}$ In contrast to this result, in our study, no difference was found between dry canal and presence of tested irrigation solutions. Our results supported the findings of a previous study, which stated that the Root ZX EAL was not affected by $2.5 \% \mathrm{NaOCl}^{3}$

Limited data are available evaluating iPex apex locators. Additionally, no research is available concerning the accuracy of iPex II at present. The iPex demonstrated similar accuracy to Root ZX in determining the working length, in vivo. ${ }^{17}$ The accuracy of the iPex EAL was not affected by the presence of $2.5 \% \mathrm{NaOCl}^{3}$ Our results supported this finding and demonstrated that no difference was found between the accuracy of iPex II when various irrigation solutions were used $(p=0.062)$. In determining the EWL in the present study, the Root ZX mini and iPex II were accurate 47.3 and $42.8 \%$ of the time to $\pm 0.5 \mathrm{~mm}$ respectively. Our results were quite similar to those of a previous report, in which Duran-Sindreu et $\mathrm{al}^{3}$ reported that the Root $\mathrm{ZX}$ and iPex were accurate 46.4 and $42.8 \%$, respectively, under similar conditions. The similarity between the results of both studies could be explained by the same working principles of Root ZX/ Root ZX mini and iPex/iPex II EALs.

The Raypex 6 is a new multifrequency EAL and a survey of literature showed that limited data are available to date. The Raypex 6 detects the major foramen more consistently than the apical constriction. This was explained by the sudden change in electric impedance produced when the file is displaced from within the canal to the conducting medium. ${ }^{1}$ In this study, the third green bar limit of the Raypex 6 display was considered to represent the apical constriction in accordance with a previous study ${ }^{1}$ that used the same reference. In our study, significant difference was found when Raypex 6, $\mathrm{NaOCl}$, or QMix irrigation solutions were used as irrigants. The mean EWL for $\mathrm{NaOCl}$ and QMix solutions were -0.69 and -0.50 respectively. However, both measurements could be defined as acceptable when the acceptable error range of $\pm 1 \mathrm{~mm}$ was taken. ${ }^{10}$ No difference was found between dry canal and presence of tested solutions. The results, in agreement with previous results, ${ }^{1,18}$ showed that electronic measurements in dry 
canals can be performed with results similar to those obtained in the presence of $\mathrm{NaOCl}$.

Propex technology was considered reliable in the presence of various rootcanal irrigants. ${ }^{19}$ Similarly, Propex II was found to be an accurate device in determining the actual working length. Additionally, Propex II was reported to be more accurate than the digital radiographic method..$^{20}$ The present study supported this finding and demonstrated that Propex II measured the EWL with an acceptable accuracy. In addition to this finding, when mean values were considered, Propex II demonstrated the most acceptable result in the presence of QMix solution, with a statistically significant difference. Propex II reached a $94.7 \%$ level of accuracy. This percentage was considered acceptable for clinical practice and was in accordance with a previous finding. ${ }^{21}$

QMix is a new irrigation solution and the influence of this solution on the accuracy of EALs has not been tested and reported to date. Various studies evaluated the efficacy of this newly developed solution in terms of effect on root canal dentin, ${ }^{22}$ smear layer removal, ${ }^{23}$ and antimicrobial activity. ${ }^{6}$ According to the results of these studies, the QMix solution demonstrated promising results and has potential as a commonly used endodontic irrigant. Irrigation with $\mathrm{NaOCl}$ after demineralizing agents causes dentinal erosion. ${ }^{24}$ Therefore, irrigation with a combination product, such as QMix provides dentinal surface without erosion and simplifies the irrigation protocol. ${ }^{6} \mathrm{QMix}$ was recommended as a final rinse after $\mathrm{NaOCl} .{ }^{6}$ However, in addition to its superior smear layer removing property, the solution was reported to be as effective as $6 \%$ sodium hypochlorite against E. faecalis in dentinal tubules. ${ }^{25}$ It could be hypothesized that depending on properties, QMix irrigation may be recommended for not only final irrigation, but also in earlier stages of root canal treatment. Accordingly, QMix may be a suitable irrigation solution during working length determination with EALs. Propex II and Raypex 6 demonstrated more accurate measurements than iPex II and Root ZX mini when $\pm 0.5 \mathrm{~mm}$ was considered as acceptable in the presence of QMix solution. However, iPex II demonstrated comparable results when compared with the measurements in the presence of $\mathrm{NaOCl}$. Additionally, all tested EAL devices demonstrated reliable results when $\pm 1 \mathrm{~mm}$ was considered acceptable.

\section{CONCLUSION}

Depending on the results, the null hypothesis could be accepted and EAL measurements were not adversely affected in the presence of QMix. Measurements were within the $\pm 1 \mathrm{~mm}$ clinical tolerance range; all devices can be considered reliable when used with QMix irrigation solution and with any irrigant.

\section{REFERENCES}

1. Lucena C, López JM, Martín JA, Robles V, González-Rodríguez MP. Accuracy of working length measurement: electronic apex locator versus cone-beam computed tomography. Int Endod J 2014 Mar;47(3):246-256.

2. Kim YJ, Chandler NP. Determination of working length for teeth with wide or immature apices: a review. Int Endod J 2013 Jun;46(6):483-491.

3. Duran-Sindreu F, Gomes S, Stöber E, Mercadé M, Jané L, Roig M. In vivo evaluation of the iPex and Root ZX electronic apex locators using various irrigants. Int Endod J 2013 Aug;46(8):769-774.

4. Kaufman AY, Keila S, Yoshpe M. Accuracy of a new apex locator: an in vitro study. Int Endod J 2002 Feb;35(2): 186-192.

5. Elnaghy AM. Effect of QMix irrigant on bond strength of glass fibre posts to root dentine. Int Endod J 2014 Mar;47(3): 280-289.

6. Stojicic S, Shen Y, Qian W, Johnson B, Haapasalo M. Antibacterial and smear layer removal ability of a novel irrigant, QMiX. Int Endod J 2012 Apr;45(4):363-371.

7. Somma F, Castagnola R, Lajolo C, Paternò Holtzman L, Marigo L. In vivo accuracy of three electronic root canal length measurement devices: Dentaport ZX, Raypex 5 and ProPex II. Int Endod J 2012 Jun;45(6):552-556.

8. Shabahang S, Goon WW, Gluskin AH. An in vivo evaluation of Root ZX electronic apex locator. J Endod 1996 Nov;22(11): 616-618.

9. Stoll R, Urban-Klein B, Roggendorf MJ, Jablonski-Momeni A, Strauch K, Frankenberger R. Effectiveness of four electronic apex locators to determine distance from the apical foramen. Int Endod J 2010 Sep;43(9):808-817.

10. Real DG, Davidowicz H, Moura-Netto C, Zenkner Cde L, Pagliarin CM, Barletta FB, de Moura AA. Accuracy of working length determination using 3 electronic apex locators and direct digital radiography. Oral Surg Oral Med Oral Pathol Oral Radiol Endod 2011 Mar;111(3): e44-e49.

11. Lucena-Martín C, Robles-Gijón V, Ferrer-Luque CM, de Mondelo JM. In vitro evaluation of the accuracy of three electronic apex locators. J Endod 2004 Apr;30(4): 231-233.

12. Duran-Sindreu F, Stöber E, Mercadé M, Vera J, Garcia M, Bueno R, Roig M. Comparison of in vivo and in vitro readings when testing the accuracy of the Root ZX apex locator. J Endod 2012 Feb;38(2):236-239.

13. Silveira LF, Petry FV, Martos J, Neto JB. In vivo comparison of the accuracy of two electronic apex locators. Aust Endod J 2011 Aug;37(2):70-72.

14. D'Assunção FLC, Albuquerque DS, Ferreira LCQ. The ability of two apex locators to locate the apical foramen: an in vitro study. J Endod 2006 Jun;32(6):560-562.

15. Koçak S, Koçak MM, Sa lam BC. Efficiency of 2 electronic apex locators on working length determination: A clinical study. J Conserv Dent 2013 May-Jun;16(3):229-232.

16. Haffner C, Folwaczny M, Galler K, Hickel R. Accuracy of electronic apex locators in comparison to actual length-an in vivo study. J Dent 2005 Sep;33(8):619-625. 
17. Stöber EK, Duran-Sindreu F, Mercadé M, Vera J, Bueno R, Roig M. An evaluation of root ZX and iPex apex locators: an in vivo study. J Endod 2011 May;37(5):608-610.

18. Gomes S, Oliver R, Macouzet C, Mercadé M, Roig M, DuranSindreu F. In vivo evaluation of the Raypex 5 by using different irrigants. J Endod 2012 Aug;38(8):1075-1077.

19. Kang JA, Kim SK. Accuracies of seven different apex locators under various conditions. Oral Surg Oral Med Oral Pathol Oral Radiol Endod 2008 Oct;106(4):e57-e62.

20. Cianconi L, Angotti V, Felici R, Conte G, Mancini M. Accuracy of three electronic apex locators compared with digital radiography: an ex vivo study. J Endod 2010 Dec;36(12): 2003-2007.

21. Plotino G, Grande NM, Brigante L, Lesti B, Soma F. Ex vivo accuracy of three electronic apex locators: Root ZX, elements diagnostic unit and apex locator and Propex. Int Endod J 2006 May;39(5):408-414.
22. Aranda-Garcia AJ, Kuga MC, Chavéz-Andrade GM, KalatzisSousa NG, Hungaro Duarte MA, Faria G, Reis Só MV, Faria NB Jr. Effect of final irrigation protocols on microhardness and erosion of root canal dentin. Microsc Res Tech 2013 Oct;76(10):1079-1083.

23. Dai L, Khechen K, Khan S, Gillen B, Loushine BA, Wimmer CE, Gutmann JL, Pashley D, Tay FR. The effect of QMix, an experimental antibacterial root canal irrigant, on removal of canal wall smear layer and debris. J Endod 2011 Jan;37(1): 80-84.

24. Qian W, Shen Y, Haapasalo M. Quantitative analysis of the effect of irrigant solution sequences on dentin erosion. J Endod 2011 Oct;37(10):1437-1441.

25. Ma J, Wang Z, Shen Y, Haapasalo M. A new noninvasive model to study the effectiveness of dentin disinfection by using confocal laser scanning microscopy. J Endod 2011 Oct;37(10):1380-1385. 